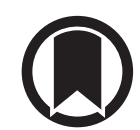

CrossMark

\title{
Prognostic significance of chronic respiratory symptoms in individuals with normal spirometry
}

To the Editor:

The study by ÇOLAK et al. [1] concludes that chronic respiratory symptoms are associated with respiratory hospitalisations and death in individuals with normal spirometry without known airway disease. Whilst guideline-led spirometric diagnostic criteria revolve around the ratio of forced expiratory volume in $1 \mathrm{~s}$ $\left(\mathrm{FEV}_{1}\right)$ to forced vital capacity $(\mathrm{FVC})$, in a recent study we concluded that almost a third of patients with a diagnosis of COPD in primary care do not meet those criteria [2]. Whilst a proportion of those could be due to poor spirometry technique, FVC is a difficult manoeuvre to perform. Our study supports the finding of ÇoLAK et al. [1] in that airflow obstruction as defined by $\mathrm{FEV}_{1} / \mathrm{FVC}$ may be a poor diagnostic tool. Two thirds of our patients with normal ratio had abnormal $\mathrm{FEV}_{1} \%$ predicted. In the presence of normal chest radiography and examination, perhaps $\mathrm{FEV}_{1}$ is a better diagnostic marker of COPD in primary care.

In patients with normal ratio and $\mathrm{FEV}_{1} \%$ predicted, rather than trying to diagnose COPD without obstruction(!), it is surely better to consider alternative chronic symptoms such as chronic cough. The recent publication of the guidelines from the European Respiratory Society task force on chronic cough suggests that this disease is poorly recognised and we would argue that the majority of patients in the study by ÇOLAK et al. [1] will actually have a diagnosis of chronic cough [3]. If the diagnostic criteria and the treatment recommendation within the cough guidelines are applied, perhaps a reduction in the morbidity and mortality described by ÇoLAK et al. [1] can be achieved by a correct diagnosis and applying appropriate treatment.

@ERSpublications

In the presence of normal CXR and examination perhaps $\mathrm{FEV}_{1}$ is a better diagnostic marker of COPD in primary care http://bit.ly/2QAUpSA

Cite this article as: Hamad G, Rigby A, Morice AH. Prognostic significance of chronic respiratory symptoms in individuals with normal spirometry. Eur Respir J 2020; 55: 1902093 [https://doi.org/10.1183/ 13993003.02093-2019].

Ghassan Hamad $^{1}$, Alan Rigby ${ }^{2}$ and Alyn H. Morice ${ }^{1}$

${ }^{1}$ Hull York Medical School, Castle Hill Hospital, Hull, UK. ${ }^{2}$ Hull York Medical School, University of Hull, Castle Hill Hospital, Hull, UK. ${ }^{3}$ Hull York Medical School, Castle Hill Hospital, Hull, UK.

Correspondence: Ghassan Hamad, University of Hull, Respiratory Medicine Dept, Castle Hill Hospital, Hull, HU6 7RX, UK. E-mail: ghassanhamad@yahoo.co.uk

Received: 04 Nov 2019 | Accepted after revision: 15 Nov 2019

Conflict of interest: G. Hamad reports institutional grants from AstraZeneca during the conduct of the study. A. Rigby has nothing to disclose. A.H. Morice reports grants from AstraZeneca, during the conduct of the study.

\section{References}

1 Çolak Y, Nordestgaard BG, Vestbo J, et al. Prognostic significance of chronic respiratory symptoms in individuals with normal spirometry. Eur Respir J 2019; 54: 1900734.

2 Morice AH, Hamad GA. Personalised prescribing for COPD patients: a primary care audit. Eur Respir J 2017; 50: Suppl. 61, PA925.

3 Morice AH, Millqvist E, Bieksiene K, et al. ERS guidelines on the diagnosis and treatment of chronic cough in adults and children. Eur Respir J 2020; 55: 1901136. 
From the authors:

We thank G. Hamad, A. Rigby and A.H. Morice for their interest in our study [1]. They raise some interesting points related to difficulties of spirometry performance and underdiagnosis of COPD, and poor recognition of chronic cough.

We agree that difficulties in spirometry performance can easily lead to underdiagnosis of COPD [2-4]. Since airflow limitation in COPD is defined as a low ratio of forced expiratory volume in $1 \mathrm{~s}\left(\mathrm{FEV}_{1}\right)$ and forced vital capacity (FVC), many physicians, including general practitioners, may only focus on this measurement alone. However, patients with COPD often perform insufficiently during spirometry due to exhaustion or severe airflow limitation. Nonetheless, common sense dictates that individuals complaining of chronic respiratory symptoms with a normal spirometry should be reassessed within a short time period and, if symptoms persist, they should be referred to additional diagnostic assessment; preferably, to units with experience in advanced lung function measurements and other modalities, such as computed tomography imaging, to diagnose obstructive lung disease.

Even with a normal ratio of $\mathrm{FEV}_{1}$ to $\mathrm{FVC}$, a substantial proportion of patients with COPD will demonstrate low $\mathrm{FEV}_{1}$ and/or FVC, a condition termed preserved ratio impaired spirometry (PRISm). Recently, individuals with PRISm have been observed with poor survival, and some of them fulfil airflow limitation criteria for COPD after relatively short follow-up time [5, 6]. Interestingly, individuals with normal spirometry but with chronic respiratory symptoms were still observed with poor prognosis after adjustment for lung function in our study [1], suggesting that PRISm alone is unlikely to explain our findings.

We agree that chronic cough is underdiagnosed, and is a condition that is highly treatable after a proper diagnostic workout [7-9]. Recently, we have shown that chronic cough is highly prevalent in the general population, including among non-smokers, and most of the identified risk factors were potentially modifiable [10]. Individuals with normal spirometry reporting cough had an increased risk of respiratory hospitalisations and death in the present study, comparable to the other chronic respiratory symptoms dyspnoea, chronic mucus hypersecretion and wheezing [1]. Although cough in the present study was not defined strictly as chronic cough [7], we still believe that most symptomatic individuals had chronic cough. Again, whether it is chronic cough or any other type of chronic respiratory symptoms, individuals with persistent symptoms should be referred to additional diagnostic assessment.

@ERSpublications

Chronic respiratory symptoms in individuals with normal spirometry should lead to clinical follow-up http://bit.ly/35hOtlM

Cite this article as: Çolak Y, Afzal S. Prognostic significance of chronic respiratory symptoms in individuals with normal spirometry. Eur Respir J 2020; 55: 1902226 [https://doi.org/10.1183/ 13993003.02226-2019].

Yunus Çolak and Shoaib Afzal

Dept of Clinical Biochemistry and the Copenhagen General Population Study, Herlev and Gentofte Hospital, Copenhagen University Hospital, Herlev, Denmark.

Correspondence: Shoaib Afzal, Herlev and Gentofte Hospital, Copenhagen University Hospital, Dept of Clinical Biochemistry, Herlev Ringvej 75, Herlev 2730, Denmark. E-mail: shoaib.afzal@regionh.dk

Received: 18 Nov 2019 | Accepted: 19 Nov 2019

Conflict of interest: Y. Çolak reports personal fees from Boehringer Ingelheim and AstraZeneca, outside the submitted work. S. Afzal has nothing to disclose.

\section{References}

1 Çolak Y, Nordestgaard BG, Vestbo J, et al. Prognostic significance of chronic respiratory symptoms in individuals with normal spirometry. Eur Respir J 2019; 54: 1900734.

2 Çolak Y, Afzal S, Nordestgaard BG, et al. Prognosis of asymptomatic and symptomatic, undiagnosed COPD in the general population in Denmark: a prospective cohort study. Lancet Respir Med 2017; 5: 426-434.

3 Diab N, Gershon AS, Sin DD, et al. Underdiagnosis and overdiagnosis of chronic obstructive pulmonary disease. Am J Respir Crit Care Med 2018; 198: 1130-1139.

4 Aaron SD, Tan WC, Bourbeau J, et al. Diagnostic instability and reversals of chronic obstructive pulmonary disease diagnosis in individuals with mild to moderate airflow obstruction. Am J Respir Crit Care Med 2017; 196: 306-314.

5 Wan ES, Fortis S, Regan EA, et al. Longitudinal phenotypes and mortality in preserved ratio impaired spirometry in the COPDGene Study. Am J Respir Crit Care Med 2018; 198: 1397-1405. 
6 Wijnant SRA, De Roos E, Kavousi M, et al. Trajectory and mortality of preserved ratio impaired spirometry: the Rotterdam Study. Eur Respir J 2020; 55: 1901217.

7 Morice AH, Millqvist E, Bieksiene K, et al. ERS guidelines on the diagnosis and treatment of chronic cough in adults and children. Eur Respir J 2020; 55: 1901136.

8 Kastelik JA, Aziz I, Ojoo JC, et al. Investigation and management of chronic cough using a probability-based algorithm. Eur Respir J 2005; 25: 235-243.

9 Pratter MR, Bartter T, Akers S, et al. An algorithmic approach to chronic cough. Ann Intern Med 1993; 119: 977-983.

10 Çolak Y, Nordestgaard BG, Laursen LC, et al. Risk factors for chronic cough among 14,669 individuals from the general population. Chest 2017; 152: 563-573.

Copyright @ERS 2020 